\title{
Practical and Scalable Installation of Neglected S(VI) Functionality with Applications to the Enantiospecific Synthesis of Pharmaceuticals
}

\author{
Zachary P. Shultz, ${ }^{1}$ Thomas Scattolin, ${ }^{1}$ Lukasz Wojtas, ${ }^{2}$ Justin M. Lopchuk ${ }^{1,2,3 *}$ \\ ${ }^{1}$ Drug Discovery Department, H. Lee Moffitt Cancer Center and Research Institute, 12902 Magnolia Drive, Tampa, \\ FL 33612, USA. \\ ${ }^{2}$ Department of Chemistry, University of South Florida, Tampa, FL 33620, USA \\ ${ }^{3}$ Department of Oncologic Sciences, College of Medicine, University of South Florida, Tampa, FL 33612, USA.
}

\begin{abstract}
Sulfoximines and related sulfonimidoyl groups have been largely ignored for decades until their value was demonstrated in biological settings. The realization of their importance has ushered in a new wave of discovery and pharmaceutical applications. In attempts to remove the "neglected" description of the lesser-known S(VI) groups, a practical and modular approach for $\alpha$-substituted heterocycles bearing sulfonimidoyl functional groups was developed. A variety of sulfoximines containing diverse functionality and complexity were rapidly introduced in an enantiospecific fashion with good to excellent yields. Pharmaceutically important heterocyclic scaffolds were shown to undergo the facile nucleophilic substitution, while sulfoximines, sulfonimidamides and sulfondiimines were all demonstrated to be compatible nucleophiles. The utility and practicality of the method was exhibited in target- and diversity-oriented syntheses of four sulfoximine-containing pharmaceuticals including ceralasertib, an ATR inhibitor currently in clinical trials. The introduction of underexplored sulfur functionality to common heterocyclic pharmacophores provides a practical platform for rapid analog development that is expected to aid future efforts in the discovery sciences.
\end{abstract}

\section{INTRODUCTION}

The ability of sulfur to adopt a range of oxidation states (II-VI) with defined molecular geometries has led to many advancements in the discovery sciences. ${ }^{1}$ From materials to medicines, sulfur-containing functional groups are pervasive across disciplines. The more common S(VI) functional groups, such as sulfones and sulfonamides, have attracted the most attention - finding their way into many drug discovery programs and greater than 7o FDA approved drugs. ${ }^{2}$ More recently, the exploration of historically neglected sulfonimidoyl S(VI) functional groups, containing $\mathrm{S}=\mathrm{N}$ and $\mathrm{S}$ $\mathrm{N}$ bond(s), has provided novel clinical candidates for a variety of indications as well as important agrochemicals (Figure 1.). ${ }^{3}$

Sulfoximines, the mono-aza $\mathrm{S}=\mathrm{N}$ variants of sulfones (found in 1-5), ${ }^{4}$ have recently been accepted in medicinal chemistry as viable bioisosteres for carboxylic acids, alcohols and sulfones (Figure $1 \mathrm{~B}$ ). ${ }^{3 \mathrm{a}, 5}$ Additionally, sulfonimidamides can serve as bioisoteres for amines, sulfones and sulfonamides. ${ }^{3 \mathrm{~d}, 6}$ The unique $\mathrm{H}$-bond donor and acceptor properties of the sulfonimidoyl groups allow them to mimic a wide range of other functionality while commonly providing other advantages, such as a chiral environment and increases in aqueous solubility. ${ }^{3 \mathrm{~d}, 7}$ Recent enthusiasm over the physiochemical properties of sulfoximines (and other sulfonimidoyl groups $)^{3 f}$ has led to an exponential increase in their use to improve pharmacokinetic (PK) and pharmacodynamic (PD) properties during lead optimization studies. ${ }^{3 \mathrm{a}-\mathrm{c}, 8}$

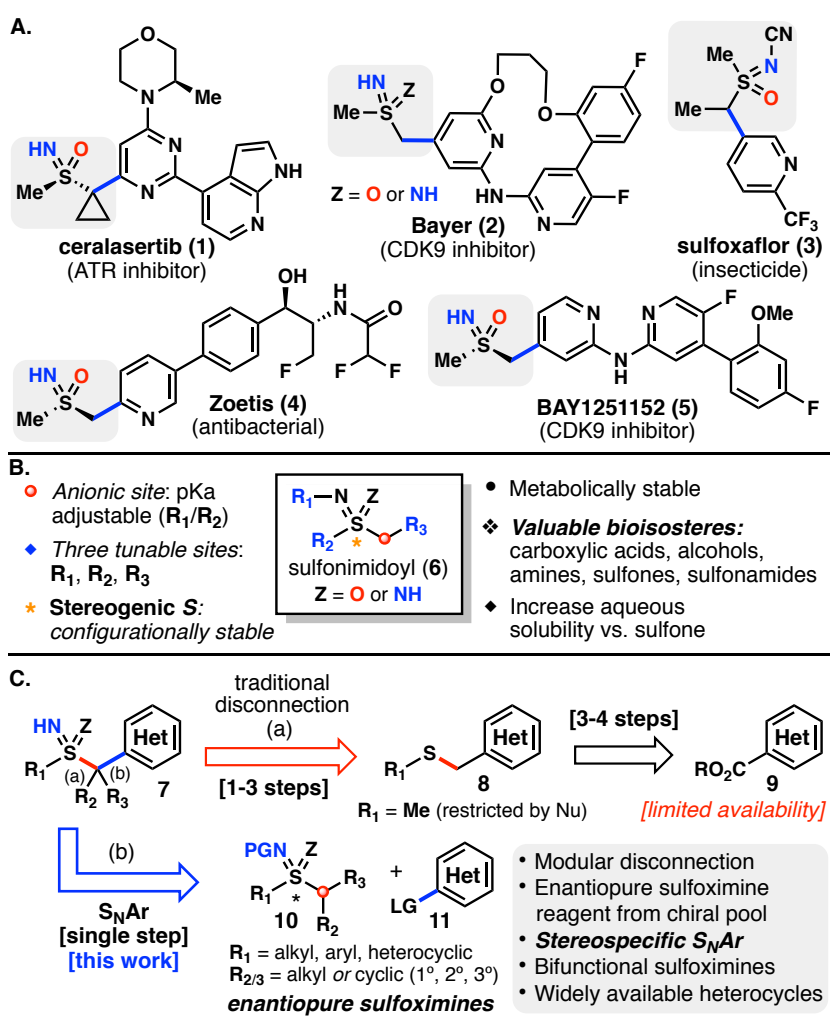

Figure 1. (A) Biologically active heterocycles containing $\alpha$ substituted sulfonimidoyl functional groups. (B) Structural and physiochemical features of sulfonimidoyls. (C) Different disconnections to install sulfonimidoyl functional groups. 
A specific example of this was demonstrated by AstraZeneca during the discovery and subsequent development of their ATR inhibitor, ceralasertib (1).$^{4 \mathrm{a}}$ Amid the final optimization stage of preclinical development, a sulfone was replaced for a sulfoximine. The resulting introduction of a sulfoximine led to an increased aqueous solubility while maintaining potency, which allowed for the advancement of $\mathbf{1}$ to the clinic where it is currently undergoing multiple phase II clinical trials. ${ }^{9}$ Other discovery programs at Bayer, ${ }^{4 b-c, f, 10}$ Pfizer, ${ }^{11}$ Genentech, ${ }^{12}$ Hoffman-La Roche, ${ }^{13}$ Novartis, ${ }^{14}$ Nestlé Skin Health ${ }^{15}$ and Corteva Agriscience, ${ }^{16}$ have been actively researching neglected S(VI) functional groups with respect to methods for their installation and incorporation into lead scaffolds.

Furthermore, the novelty of sulfonimidoyl groups, with their inherent stereochemical and additional spatial vectors capable of modifications, provides ample opportunities for new intellectual property (IP) development. An increase in patent applications and issuances within the last ten years is a growing testament to the untapped potential of sulfoximines (2,074 total patents since their first report in $1953,1,536$ of those coming in the last decade $)^{17}$, sulfonimidamides ( 140 total patents since their first report in $1967,121$ of those coming in the last decade $)^{18}$, sulfondiimines (33 total patents since their first report in 1967, 18 of those coming in the last decade) ${ }^{19}$ and related functional groups. Pioneering work by Bolm, ${ }^{20}$ Bull, ${ }^{21}$ Johnston, ${ }^{22}$ Luecking, ${ }^{23}$ Maruoka, ${ }^{24}$ Sharpless, ${ }^{25}$ Willis ${ }^{26}$ and others for the creation and modifications of S(VI) functionality has given rise to new possibilities in the field. ${ }^{27} \mathrm{How}-$ ever, despite the increase in methods to access neglected sulfonimidoyl-containing compounds, there has been relatively little advancement toward the modular installation of these groups to pharmaceutical scaffolds.

Owing to the growing attention of higher order sulfurbased functional groups as bioisosteres and PK modulators in the pharmaceutical sciences, the unmet need for their incorporation into medicinally relevant structures with an emphasis on asymmetric control must be addressed. Traditional methods to introduce $\alpha$-substituted sulfonimidoyl units relies on $\mathrm{S}-\mathrm{C}$ bond disconnection (a) (Figure $\mathrm{iC}$ ) involving a laborious 4-6 step synthetic sequence from carboxylic acids or esters. ${ }^{4 a-c, e-f}$ Limitations of disconnection (a) include the lengthy step count, challenging asymmetric control at the stereogenic $S$-center and the difficulty of late-stage modifications at sulfur - the last of which explains the high prevalence of methyl substituted sulfoximines and sulfondiimines. Other methods for the synthesis of $\alpha$-arylated sulfoximines rely on exotic transition metal-catalyzed systems and conditions accompanied by limited scope with respect to both sulfoximines and aryl coupling partners - especially with regards to heterocycles. $^{23 a, 28}$

To address the aforementioned limitations and provide a modular approach to aid in discovery efforts, a straightforward solution was sought that can be applied to readily available pharmaceutically relevant heterocyclic building blocks. Disconnection (b) (Figure ${ }_{1} C$ ) outlines an $\mathrm{S}_{\mathrm{N}} \mathrm{Ar}$ approach for the installation of $\alpha$-substituted sulfonimidoyl functionality to widely available electrophilic heterocycles.
This alternative disconnection will provide discovery chemists with a multifunctional method for the introduction of highly oxidized neglected sulfur moieties of varying complexity in a single step. The utilization of enantiopure sulfonimidoyl nucleophiles grants an enantiospecific entry into $\alpha$-heteroarylated products that will transform the targeted synthesis process, relieving the pressure of relying on chiral separation techniques and loss of material.

\section{DEVELOPMENT AND SCOPE}

The requisite sulfoximines were accessible from the direct oxidation/imination of sulfides or sulfoxides via Bull's sulfoximine synthesis, ${ }^{21 \mathrm{C}}$ followed by $\mathrm{N}-\mathrm{H}$ protection (Figure $2 \mathrm{~A}$ ). Although the modern method developed by Willis for the synthesis of sulfondiimines could be used to access dimethyl sulfondiimine $16,{ }^{26 \mathrm{~b}}$ the direct imination of dimethyl sulfide with $t$-BuOCl and $\mathrm{NH}_{3}$ was chosen for this application. ${ }^{29}$ Orthogonally protected sulfonimidamide 20 was made available from a 4 step procedure starting from disulfide 18. Chiral alkyl sulfoximines can be made readily

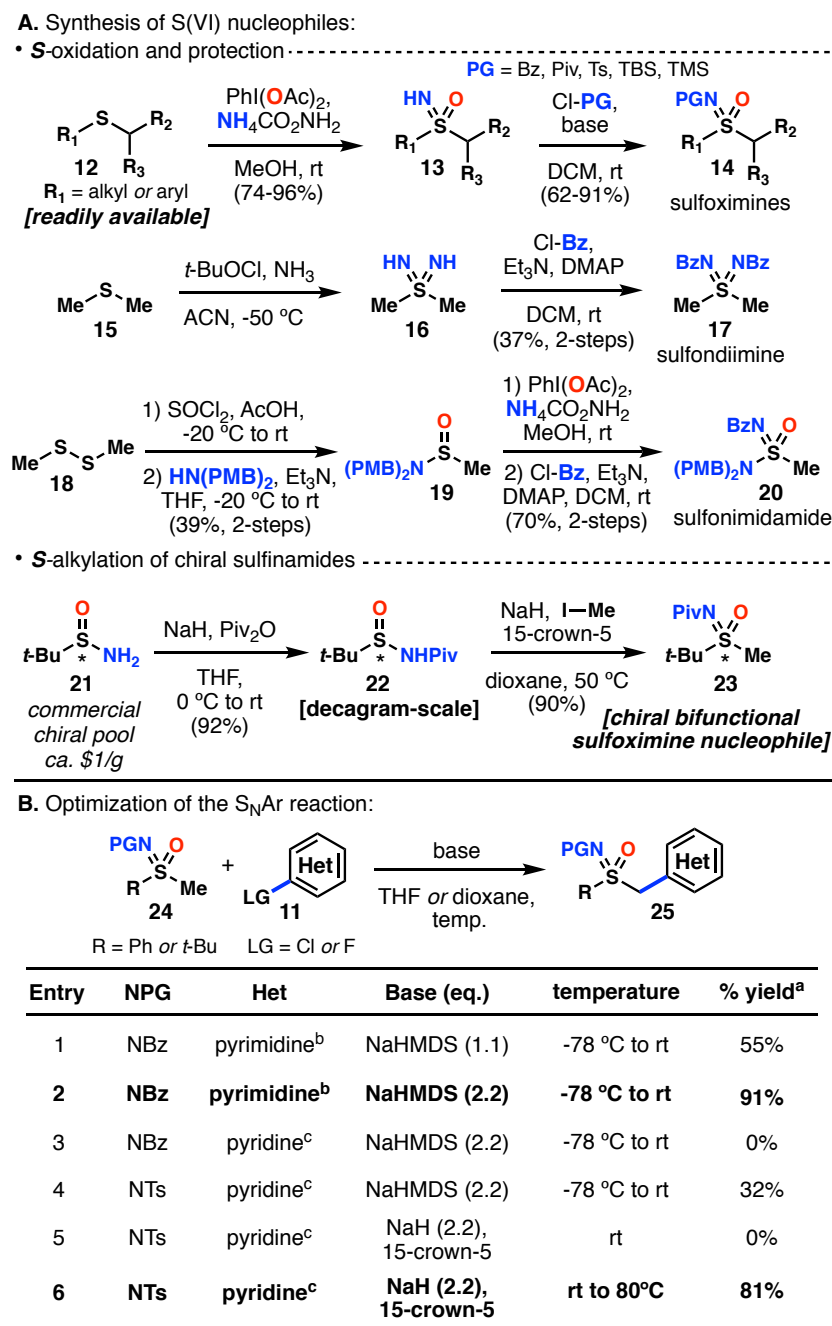

Figure 2. (A) Synthetic routes to access S(VI) nucleophiles. (B) Optimization of sulfonimidoyl $\mathrm{S}_{\mathrm{N}} \mathrm{Ar}$ conditions with heterocycles. All reactions were performed on $0.25 \mathrm{mmol}$ scale. a Isolated yields. ${ }^{\mathrm{b}}$ 4,6-Dichloro-2-(methylthio)pyrimidine was used. ' 2-Fluoropyridine was used. THF was used with NaHMDS. Dioxane was used with $\mathrm{NaH}$ and 15 -crown-5 ether. 
available via Maruoka's $S$-alkylation strategy from $N$-Piv protected sulfinamide 22. ${ }^{24 a}$ Enantiopure $t$-Bu methyl sulfoximine 23 provides a chiral bifunctional sulfoximine linchpin, which will be highlighted in the synthetic applications below. To maintain the practical nature of an $\mathrm{S}_{\mathrm{N}} \mathrm{Ar}$ approach, we sought a general, operationally simple and scalable procedure that could be carried with minimal manipulations.

A variety of bases and reaction conditions were screened (see Supplementary Information for full reaction screen) with respect to the $\mathrm{S}(\mathrm{VI})$ nucleophile $\mathbf{2 4}$ and electrophilic heterocycles 11 (Figure $2 \mathrm{~B}$, entries 1-6). Two different procedures, cryogenic (NaHMDS, $-78^{\circ} \mathrm{C}$, entries 1-4) and thermal $\left(\mathrm{NaH} / 15\right.$-crown $-5,50-80^{\circ} \mathrm{C}$, entry 6$)$, were found to be compatible with a wide range of electrophilic heterocycles. Both methods were designed for ease of use by premixing the nucleophile and electrophile followed by the addition of base. Due to the increased acidity of the $\alpha-\mathrm{H}$ in the $\mathrm{S}_{\mathrm{N}} \mathrm{Ar}$ product 25 relative to the $\mathrm{S}(\mathrm{VI})$ nucleophile $\mathbf{2 4}$, at least 2 equivalents of base (entry 2) are required for $1^{\circ}$ and $2^{\circ}$ nucleophiles (1.1-1.5 equivalent for $3^{\circ}$ ) to obtain full conversions and high yields (up to 99\%). Thermal conditions were employed for less electron-deficient heterocycles (entry 6), such as pyridines, that were unable to undergo the $\mathrm{S}_{\mathrm{N}} \mathrm{Ar}$ reaction at room temperature (heating the reaction mixtures with NaHMDS lead to decomposition and side product formation). In nearly all cases, a 1:1 stoichiometry of nucleophile and electrophile provides good to excellent yields under the optimized reaction conditions.

With two procedures in hand that provide reactivity with electron-deficient and (relatively) more electron-rich heterocycles, the S(VI) nucleophile scope was investigated (Table 1). Symmetrical pyrimidine $\mathbf{2 6}$ was chosen to be the model heterocyclic electrophile due to its electronic nature as well as a practical scaffold for further synthetic manipulation. Various protecting groups including hydrolytically cleavable groups ( $N-\mathrm{Bz}, \mathbf{2 8}$; $N$-COp-tol, 29), commonly used tosyl group $(N-\mathrm{Ts}, 30)$ and silyl groups $(N-\mathrm{TBS}, \mathbf{3 2} ; \mathrm{N}$ TMS, 35) were compatible to provide good to excellent yields (Table 1.). When an $N$-TMS protecting group is employed, silyl group cleavage is observed under the work-up conditions to provide free sulfoximine $36(\mathrm{~N}-\mathrm{H})$ in $77 \%$ yield, allowing for the introduction and deprotection of a sulfoximine unit to heterocycles in a single step. $N$-Cyano $(\mathrm{N}$-CN, 37) sulfoximines, a commonly used imino $\mathrm{N}$-substituent, ${ }^{30}$ undergo the $\mathrm{S}_{\mathrm{N}}$ Ar smoothly in high yields (86\%).

A myriad of $N$-Bz protected sulfoximines were screened to provide a wide nucleophile scope as seen in Table 1. Sulfonimidoyl $\mathrm{S}_{\mathrm{N}} \mathrm{Ar}$ is not limited to the previously mentioned primary sulfoximines. Both secondary $(39,47)$ and tertiary dimethyl sulfoximine (41) examples resulted in the desired $\mathrm{S}_{\mathrm{N}} \mathrm{Ar}$ product in high yields. Cyclic $\alpha$-substituted nucleophiles, such as cyclopropyl $(\mathbf{4 1}, \mathbf{4 2})$, cyclobutyl (43) oxetane (44) and azetidine (45) provided sterically congested heterocyclic sulfoximines with increased molecular complexity in a single step. Chiral sulfoximines (48-51) were investigated and determined to undergo an enantiospecific $\mathrm{S}_{\mathrm{N}} \mathrm{Ar}$ reaction with pyrimidine $\mathbf{2 6}$ on gram-scale and in high yields $(75-90 \%)$. The utility of this transformation is two- fold: 1) introduction of an asymmetric sulfoximine unit without erosion of enantiopurity (as determined by chiral HPLC, see Supplementary Information) and 2) capability of further modifications at sulfur upon $t$-Bu cleavage, providing a platform for late-stage diversifications.

Arene-substituted sulfoximines containing electron donating and withdrawing groups were well tolerated (5254). As expected, the presence of other acidic functionality $(\mathrm{O}-\mathrm{H}$ or $\mathrm{N}-\mathrm{H})$ and enolizable groups (MeCO-R) were not compatible. Protection of these reactive groups, such as acetonide 55, provides access to masked carbonyl groups that can be later manipulated. Heterocycle-containing sulfoximines including pyridyl substituents $(\mathbf{5 6}, \mathbf{5 7})$, a saccharin analog $(\mathbf{5 8})$, and benzothiazine oxide (59) can be appended to other heterocyclic moieties in good yields (65$82 \%)$. In the cases of 58 and 59 , method B was required due to the poor solubility of the nucleophiles at low temperatures. Cyclic aliphatic sulfoximine $\mathbf{6 o}$ and those containing heteroatoms $(\mathbf{6 1}, \mathbf{6 2})$ were also compatible and gave diastereomeric mixtures (ca. 4:1 to 1:1) in good yields (62-78\%).

With an established sulfoximine scope, we turned our attention to neglected sulfonimidamides and sulfondiimines to determine their compatibility under our optimized $\mathrm{S}_{\mathrm{N}} \mathrm{Ar}$ conditions. Orthogonally-protected sulfonimidamide 63 proved to be a suitable nucleophile that give the desired $\mathrm{S}_{\mathrm{N}} \mathrm{Ar}$ product in $82 \%$ yield - the first example of the direct installation this functional group to a heterocycle. The bis $N$-Bz protected sulfondiimine $\mathbf{6 4}$ was also a suitable nucleophile using both method A ( $65 \%$ yield) and method B (92\% yield). Classical oxidized sulfur groups, such as sulfonamides, sulfones and sulfoxides afforded the expected $\mathrm{S}_{\mathrm{N}} \mathrm{Ar}$ products in $77-99 \%$ yields $(\mathbf{6 5}-\mathbf{6 9})$. The six different gram-scale examples found in Table 1 demonstrate the scalability of the method without a diminishment in yield.

Next, the electrophilic scope with regards to common place heterocyclic scaffolds in drug discovery was investigated. Three different sulfoximines were used to interrogate electrophilic reactivity, each with a different protecting group that proved critical (Table 2). For most electron deficient systems (e.g. triazines and pyrimidines), a benzoyl $(N-B z)$ protecting group sufficed. For less reactive substrates, benzoyl transfer to the sulfoximine $\alpha$-carbon was observed. To eliminate protecting group transfer, more robust PGs, such as pivaloyl ( $N$-Piv) and tosyl $(N-T s)$, were used. The use of both methods A and B allowed for an extensive electrophile scope that delivered a large variety of sulfoximine-containing heterocycles.

Electron-deficient ring systems known to readily undergo $\mathrm{S}_{\mathrm{N}} \mathrm{Ar}$ chemistry were first examined. Substituted 1,3,5-triazine (72) served as an excellent substrate along with pyrimidines that were substituted with electron donating groups $(\mathbf{7 8}, \mathbf{7 9})$. When $2,4,6$-trichloropyrimidine was used as an electrophile, a mixture of regioisomers (1:2, 73:74) was observed. Regioselective nucleophilic substitution on pyrimidine ring systems was achieved by a leaving group (LG) switch from chloro to $\mathrm{SO}_{2} \mathrm{Me}$ to provide C-2 selective $\mathrm{S}_{\mathrm{N}} \mathrm{Ar}$ products $\mathbf{7 4}$ and $\mathbf{7 5}$ in high yields $(93 \%$ and $89 \%)$. 

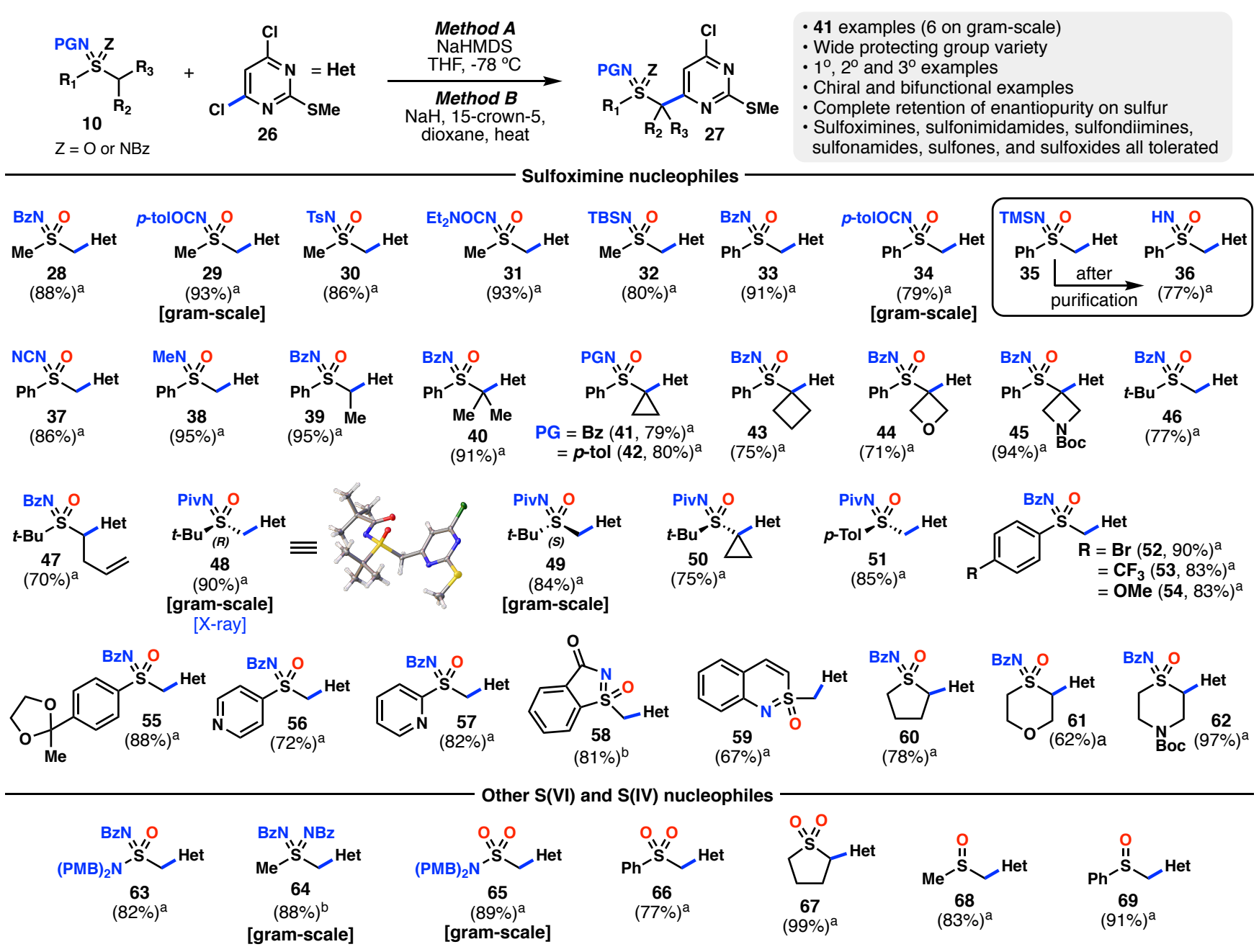

Table 1. Nucleophile scope containing sulfoximines and other S(VI) and S(IV) nucleophiles. All reactions were performed on 0.25 mmol scale unless otherwise stated. ${ }^{\mathrm{a} M e t h o d ~ A ~ w a s ~ u s e d . ~}{ }^{\mathrm{b}}$ Method B was used.

Trifunctional 4,6-dichloro-2-iodopyrimidine provided C-4 selective displacement of a chloro over iodo leaving group to give $\mathbf{7 8}$ and $\mathbf{7 9}$ as the major products on gram-scale. The utility of both $S_{N} A r$ products, $\mathbf{7 8}$ and $\mathbf{7 9}$, will be further demonstrated in the forthcoming synthetic applications. Other 2-substituted pyrimidines decorated with naphthyl (8o) and azaindole (81) substituents resulted in the desired $\mathrm{S}_{\mathrm{N}} \mathrm{Ar}$ products in high yields $(79-89 \%)$. The diazine scope is not limited to pyrimidines; 2-chloropyrazine also served as a suitable electrophile in good yield $(\mathbf{8 2}, 71 \%)$.

Commercial and readily available pyridines were thoroughly explored. Initial attempts at affecting the sulfonimidoyl $\mathrm{S}_{\mathrm{N}} \mathrm{Ar}$ with 2-fluoropyridine under both cryogenic and thermal conditions using $N$-Bz protected sulfoximines proved unfruitful, due to Bz transfer to the sulfoximine starting material. To our delight, switching the PG to $N$-Ts made 83 accessible in $81 \%$ yield. An electrondeficient pyridine bearing a $t$-Bu ester $\left(\mathrm{CO}_{2} t-\mathrm{Bu}\right)$ at the 3position provided 84 in $72 \%$ yield. Trifluoromethyl-substituted pyridines proved troublesome under the optimized reaction conditions, reflective by a $22 \%$ Isolated yield of $\mathbf{8 5}$. However, other halogenated pyridines underwent the $\mathrm{S}_{\mathrm{N}} \mathrm{Ar}$ smoothly to afford an array of highly useful pyridine products (86-93). Preferential displacement of fluoro over chloro was demonstrated with 2-chloro-4-fluoropyridine granting site-selective 4-substitution product $\mathbf{8} 7$

When 2,4,6-trichloropyridine was used, C-2 selectivity was observed in a modest, but still serviceable, 6.6:1 ratio of $\mathbf{8 8}$ (isolated r.r.). Site selectivity can be reversed by the replacement of chloro with $-\mathrm{SO}_{2} \mathrm{Me}$ at the 4-position, where 89 was obtained in high yield $(79 \%)$ as the sole regioisomer. It should be noted that when $\mathrm{SO}_{2} \mathrm{Me}$ is used as a LG in the less reactive pyridine series, dimerization of the electrophile via $\mathrm{S}_{\mathrm{N}} \mathrm{Ar}$ with the sulfone is observed as a sideproduct (not observed with pyrimidines). Conversely, 2,4,6-trifluoropyridine was less selective for the 2-position (1.9:1 r.r.) to give 90 and 91 in 50\% and $27 \%$ yields respectively. In the case where iodide could act as a LG, demonstrated by 2,6-dichloro-4-iodopyridine, a 19:1 regioselectivity was observed favoring substitution at the 2-position to provide 92. In addition, 2-chloro-3-iodopyridine was subjected to method B to give 3-iodo pyridyl sulfoximine 93 ( $44 \%$ yield) capable of further functionalization. The polyhalopyridine substrates examined provide unique opportunities for downstream modifications, via further $\mathrm{S}_{\mathrm{N}} \mathrm{Ar}$ and/or cross-coupling chemistry, which may serve as important intermediates for future discovery efforts. 


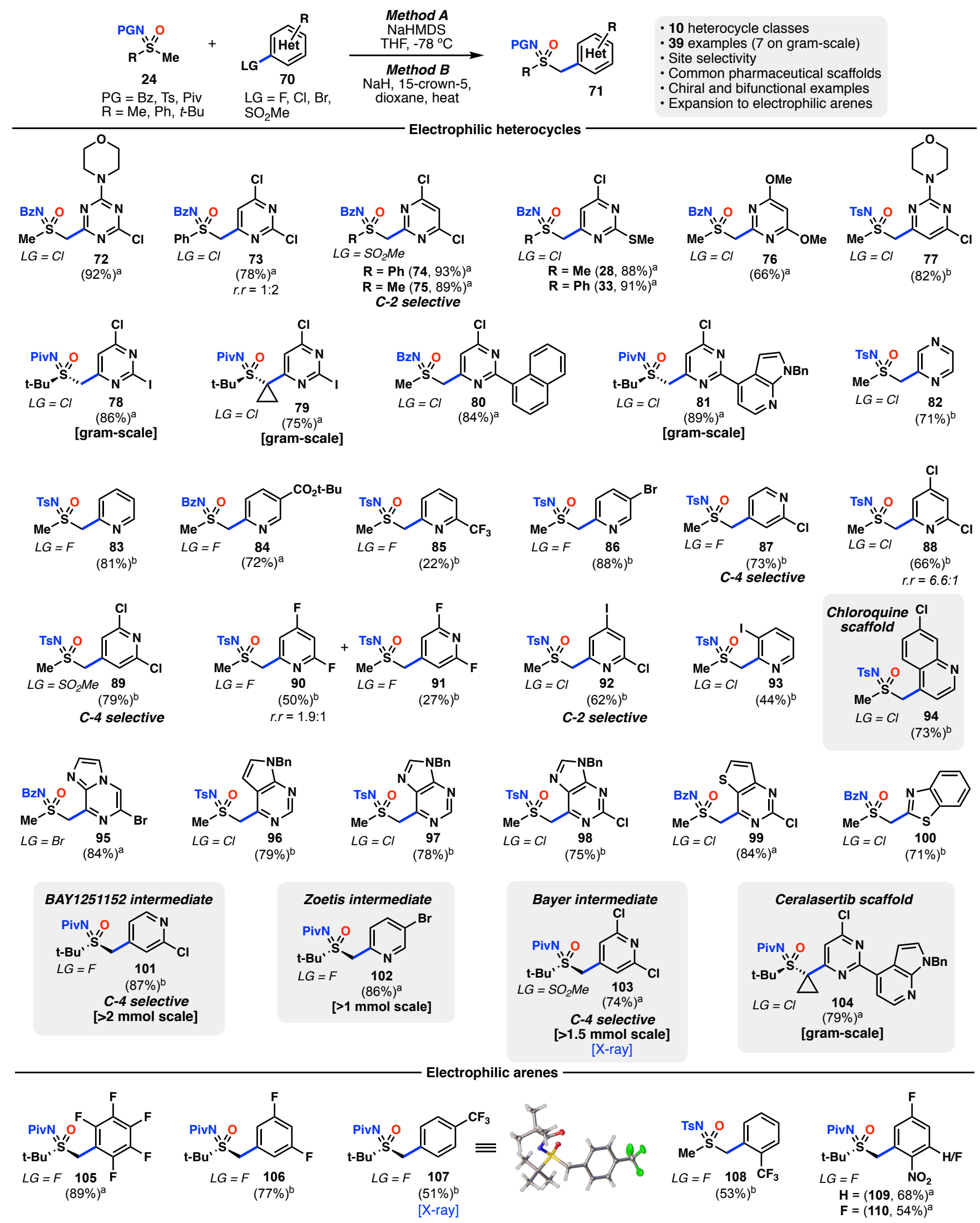

Table 2. Electrophile scope containing commonly used heterocyclic pharmacophores and electrophilic arenes. All reactions were performed on $0.25 \mathrm{mmol}$ scale unless otherwise stated. ${ }^{\mathrm{a}}$ Method A was used. ${ }^{\mathrm{b}}$ Method B was used. 
Although this work focuses on providing a straightforward and robust method for the installation of methylenelinked sulfonimidoyl functional groups to pharmaceutically relevant heterocycles, a brief exploration of arene compatibility was warranted to understand the full scope of sulfonimidoyl $\mathrm{S}_{\mathrm{N}} \mathrm{Ar}$ chemistry. As expected, hexafluorobenzene was reactive under cryogenic $\mathrm{S}_{\mathrm{N}} \mathrm{Ar}$ conditions (105, 89\% yield) while 1,3,5-trifluorobenzene was not more forceful thermal conditions were required (106, $77 \%$ yield). Interestingly, and in contrast to the pyridine example 85, 2- and 4- fluorotrifluorobenzene underwent an $\mathrm{S}_{\mathrm{N}} \mathrm{Ar}$ with method B to provide 107 and 109. To our surprise, and with modifications to the general procedure, fluoro-nitrobenzenes were able to serve as electrophiles to give sulfoximines 109 and 110 (for full reaction details and modifications see Supplementary Information). Based on a short arene screen, the scope of this transition metal-free method for the installation of S(VI) functionality is not limited to activated heterocycles but is also suitable for numerous electron-deficient arene substrates.

\section{SYNTHETIC APPLICATIONS}

Current synthetic strategies to access $\alpha$-substituted sulfoximines, and other neglected S(VI) groups, are typically arduous. Nucleophilic substitutions at activated benzylic positions by alkyl thiolates followed by oxidation to the desired sulfoximine are the most common routes, as demonstrated in the synthesis of BAY1251152 (5, Figure $3 \mathrm{~A}$, right). ${ }^{4 \mathrm{f}}$ The recent disclosure of $S$-alkylations of sulfinamides with benzylic halides developed by Maruoka can circumvent the oxidation steps (1-2 steps), while providing enantiopure sulfoximine products. ${ }^{24 a}$ In order to apply an $S$-alkylation strategy to access sulfoximines, the requisite benzylic halides (Br or I) are required via 2-3 step functionalizations of carboxylic acids or esters and is mainly limited to primary halides. An alternative $S_{N} A r$ strategy provides increased modularity and a large selection of electrophilic partners while maintaining enantiospecificity.

Bayer relied on the traditional approach, a thiolation/oxidation sequence (4 steps), to access the sulfoximine used in the synthesis of BAY1251152. Their route resulted in a racemic mixture that was separated by preparative chiral HPLC in order to access the desired target. A more modular approach utilizing a stereospecific sulfoximine installation would expedite the target synthesis and aid in future analog discovery. Sulfonimidoyl $\mathrm{S}_{\mathrm{N}} \mathrm{Ar}$ was employed in the development of a concise synthesis of BAY1251152 that is amenable for target and medicinal chemistry applications.

Beginning with commercially available 2-chloro-4-fluoropyridine (114) and our chiral bifunctional sulfoximine $(\boldsymbol{R})$ 23, $\mathrm{S}_{\mathrm{N}} \mathrm{Ar}$ method $\mathrm{B}$ gave enantiomerically pure pyridyl sulfoximine 101 in high yield $(87 \%$, Figure $3 \mathrm{~B})$. The two-step procedure for $S$-alkylation developed by Maruoka was employed to install the desired methyl (Me) sulfoximine. A previously reported method for the Buchwald-Hartwig coupling of 2-aminopyridine $1 \mathbf{1 1}^{4^{4}}$ was adopted allowing coupling to 2-chloropyridyl sulfoximine 101. Deprotection of the $N$-Piv with $\mathrm{NaOH}$ furnished BAY1251152 in $78 \%$ yield over two steps from 116. With the new sulfonimidoyl disconnection, the desired target was made accessible in 5

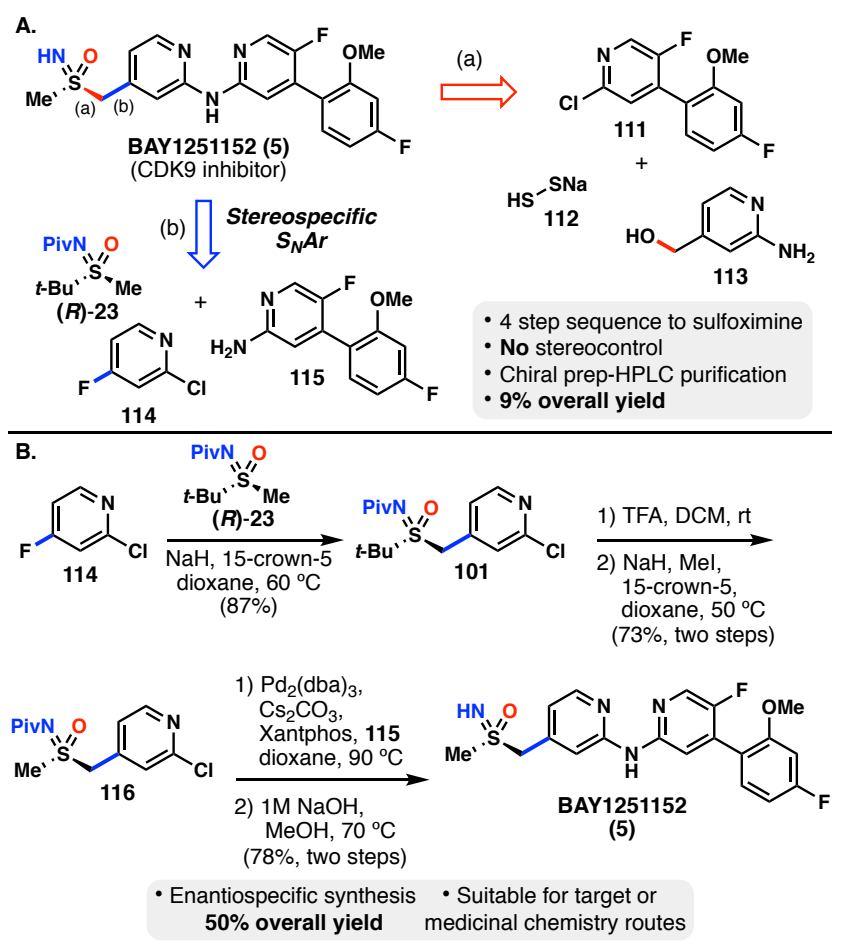

Figure 3. (A) Synthetic route analysis of BAY1251152. (B) Synthesis of BAY1251152 via sulfonimidoyl $S_{N} A r$ approach.

steps and $50 \%$ overall yield of the desired enantiomer from known starting materials - a more than five-fold increase in overall yield of $B A Y 1251152$.

Other drug discovery programs have a vested interest in evaluating the sulfoximine moiety as shown by the antibacterial candidate 4 developed by Zoetis (Figure 4$).^{4 \mathrm{e}}$ The pyridyl sulfoximine moiety 117 used in the synthesis of 4 was accessed in the traditional manner starting from benzylic alcohol 118. Bayer's macrocyclic CDK9 inhibitor 2, structurally related to BAY1251152 (5), shares a similar protected pyridyl sulfoximine building block 120. ${ }^{4 \mathrm{~b}}$ Both sulfoximine building blocks (117 and $\mathbf{1 2 0}$ ) were prepared as racemic mixtures in a 5 step sequence from either $\mathbf{1 1 8}$ or 121. ${ }^{4, b}$ By utilizing the $S_{N} A r$ approach, both pyridyl sulfoximines can be readily made as single enantiomers.

For the synthesis of Zoetis' pyridyl sulfoximine, commercially available 5-bromo-2-fluoropyridine (114) and chiral sulfoximine (R)-23 underwent a smooth $\mathrm{S}_{\mathrm{N}} \mathrm{Ar}$ using method A (102, 86\% yield). The two-step $S$-functionalization sequence provided methyl pyridyl sulfoximine 123 in $70 \%$ yield. Deprotection of the pivaloyl group under basic hydrolysis conditions gave the desired free sulfoximine $\mathbf{1 1 7}$ in $53 \%$ overall yield as a single enantiomer. A reported $\mathrm{Su}-$ zuki coupling of the requisite boronic ester with rac-117 provides access to $4 .^{4 \mathrm{e}}$ The improved route increased the overall yield of Zoetis' chiral sulfoximine intermediate from $5 \%$ to $53 \%$ overall yield and decreased the step count while providing a diversifiable intermediate for analog development ( $N$-Piv sulfinamide after $t$-Bu cleavage).

Bayer's macrocyclic CDK9 inhibitor 2 was made accessible from ( $r a c$ )-2,6-dichloropyridyl sulfoximine 120 where the protecting group was $\mathrm{Cbz}$ or $\mathrm{Boc}$ - introduced from the imination step. ${ }^{4 \mathrm{~b}}$ A pivaloyl protected 2,6-dichloropyridyl 


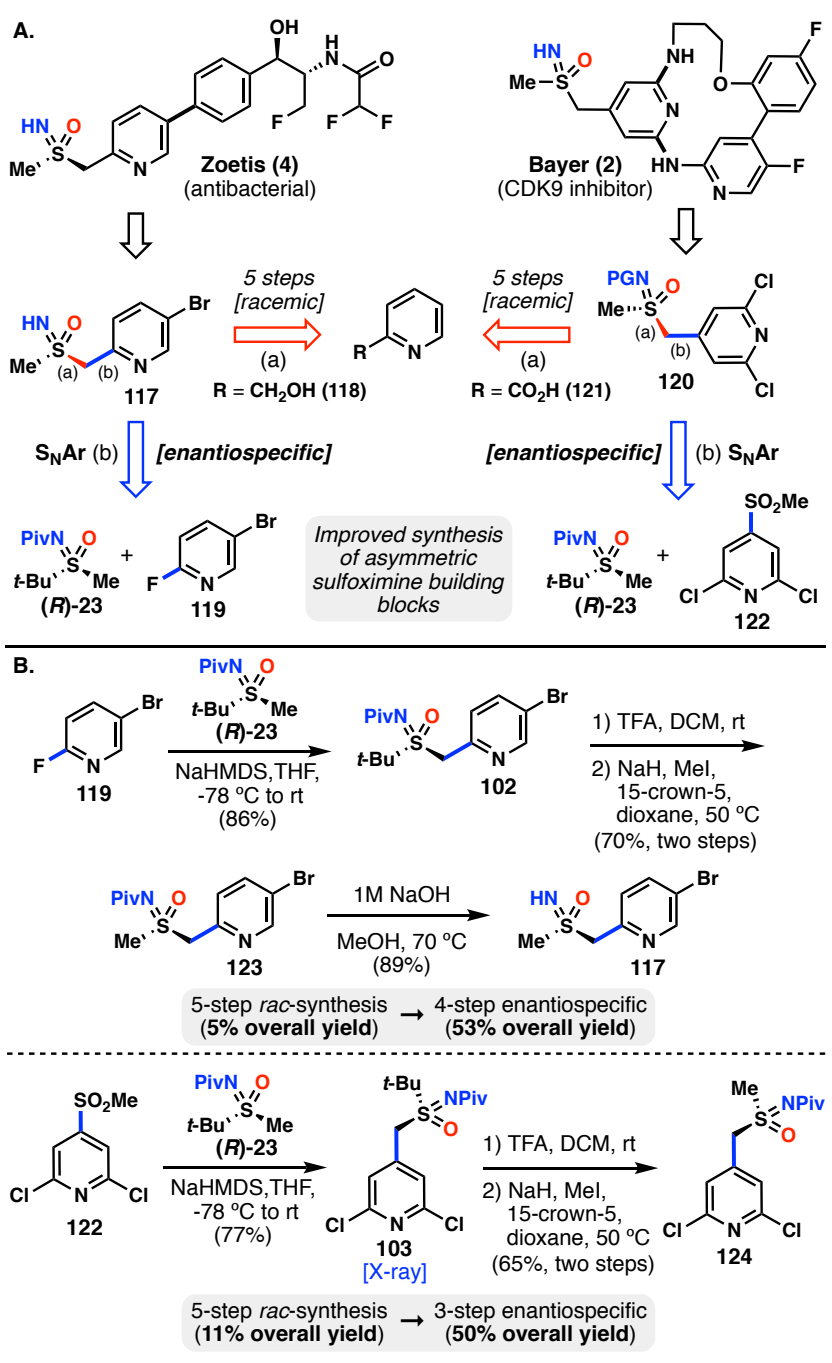

Figure 4. (A) Synthetic route analysis of antibacterial 4 and CDK9 inhibitor 2. (B) Synthesis of pyridyl sulfoximine units via sulfonimidoyl $\mathrm{S}_{\mathrm{N}} \mathrm{Ar}$.

sulfoximine should serve the same purpose and is expected to be compatible with the subsequent chemistry for the synthesis of macrocycle $\mathbf{2}$. To prepare the appropriately protected sulfoximine, pyridyl sulfone $\mathbf{1 2 2}$ and chiral sulfoximine $(\boldsymbol{R})$-23 were subjected to $\mathrm{S}_{\mathrm{N}} \mathrm{Ar}$ method A giving enantiopure $t$-Bu sulfoximine 103. The two step $S$-alkylation sequence resulted in the desired methyl pyridyl sulfoximine intermediate $\mathbf{1 2 4}$ in $50 \%$ overall yield in 3 steps from readily available starting materials. The overall yield was improved from $11 \%$ to $50 \%$ while decreasing the step count by two. This expedient 3 step synthesis of the chiral sulfoximine building block for Bayer's macrocycle CDK9 inhibitor aids in targeted synthetic efforts while providing another platform for analog development

One of the most noteworthy developments pertaining to the use of sulfonimidoyl functional groups in medicinal chemistry is the development of the AstraZeneca's ATR inhibitor ceralasertib (1). In order to provide sufficient quantities of $\mathbf{1}$ for evaluation in clinical trials, the process chemistry team at AstraZeneca (AZ) had to revamp the medicinal chemistry route that was disclosed in 2018 (Figure $5 \mathrm{~A}$, top left)..$^{\text {a }}$ Owing to the traditional method of $\alpha$-substituted sulfoximine installation, the medicinal chemistry group produced $\mathbf{1}$ (and analogs) as mixtures of diastereomers that were separated by column chromatography or iterative recrystallizations. In order to overcome the cumbersome purifications and to increase overall yield of the desired diastereomer, AZ's process team subsequently (Figure $5 \mathrm{~A}$, top right) utilized an enantioselective enzymatic oxidation to introduce the chirality at sulfur (as a sulfoxide) that was later iminated to give the desired sulfoximine functionality. ${ }^{32}$ One of the major drawbacks with their 13 step process synthesis was the installation of the cyclopropyl group in $\mathbf{1}$. As the AZ process team described: "The manufacture of AZD6738 remains a challenge for the future of this medicine, due to the difficult nature of installing the dense functionality around the pyrimidine core. Longer term it would be beneficial to have a more convergent approach with a higher yielding route". ${ }^{2}$

During the development of our sulfonimidoyl $\mathrm{S}_{\mathrm{N}} \mathrm{Ar}$ method, AZ's process team disclosed an improved route (Figure $5 \mathrm{~A}$, middle left ${ }^{33}$ and an attempt at a photocatalyzed flow approach via a Minisci reaction (Figure $5 \mathrm{~A}$, middle right) ${ }^{34}$. The newly developed process route to 1 (Figure $5 \mathrm{~A}$, middle left) addressed the issue of installing a cyclopropyl methyl sulfide moiety from $\mathbf{1 2 9}$ and $\mathbf{1 3 0}$ in a single step, while still relying on an enantioselective enzymatic oxidation. To address the remaining drawbacks of the AZ's process route, we developed an enantiospecific convergent approach utilizing our $\mathrm{S}_{\mathrm{N}} \mathrm{Ar}$ method to generate the core structure of ceralasertib (1) from enantiopure $t$-butyl cyclopropyl sulfoximine 133 and pyrimidine 134 (Figure $5 \mathrm{~A}$, bottom left). Concurrently, an alternative medicinal chemistry-oriented synthesis of 1 was developed (Figure $5 \mathrm{~A}$, bottom right) to provide multiple points of diversity that would aid in analog development for related scaffolds of $\mathbf{1}$.

The target-oriented, gram-scale synthesis of $\mathbf{1}$ (Figure ${ }_{5} \mathrm{~B}$ ) began with a Suzuki coupling between pyrimidine 135 and boronic ester 137 to deliver the azaindole pyrimidine core 134. Utilizing method A, sulfoximine 133 and pyrimidine 134 gratifyingly provided the congested pyrimidine core of $\mathbf{1}$ in a single step on multi-gram scale $(\mathbf{1 0 4}, 79 \%$ yield, $>3 \mathrm{~g}$ prepared in a single flask). A one-pot $t$-butyl cleavage/ $\mathrm{S}_{\mathrm{N}} \mathrm{Ar}$ sequence with morpholine $\mathbf{1 2 6}$ gave rise to protected sulfinamide 138 in $88 \%$ yield. The desired methyl sulfoximine arose from an $S$-alkylation with methyl iodide to afford $\mathbf{1 3 9}$. Lastly, bis-deprotection of $\mathrm{N}$-Piv and $\mathrm{N}$-Bn was realized after extensive reaction screening. A two-step optimized deprotection via acid hydrolysis of $\mathrm{N}$-Piv followed by oxidative $\mathrm{N}$-Bn cleavage resulted in $\mathbf{1}(>1 \mathrm{~g})$ with an $87 \%$ yield over two steps and one final purification.

Conversely, the diversity-oriented synthetic route highlights four distinct sites and advanced intermediates that can be exploited for analog development (Figure ${ }_{5} \mathrm{C}$ ). Enantiopure $t$-Bu pyrimidyl sulfoximine $\mathbf{7 8}$ was made accessible on gram-scale from trifunctional pyrimidine 135 in $86 \%$ yield using method $A$. At this stage, an alkylation at the benzylic position, a second $S_{N} A r$ on the pyrimidine or a cross-coupling are all options. Functionalization of the benzylic position was chosen as the second step (see Scheme $\mathrm{S}_{7}$ in SI for alternative routes) via alkylation with 1,2-dibromoethane (140) to give 79 in good yield (72\%). 
A. Approaches to ceralasertib

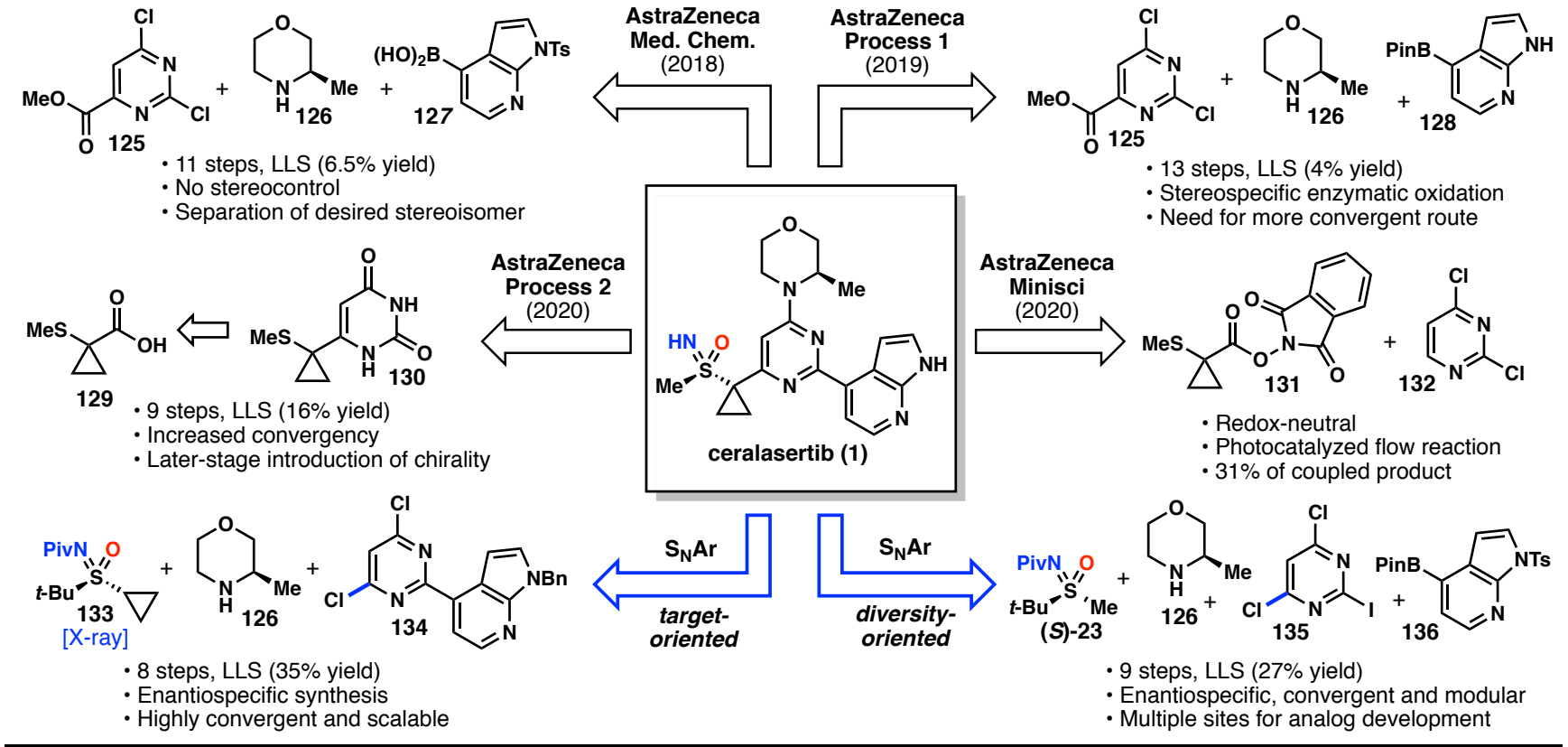

B. Target-oriented route (gram-scale)

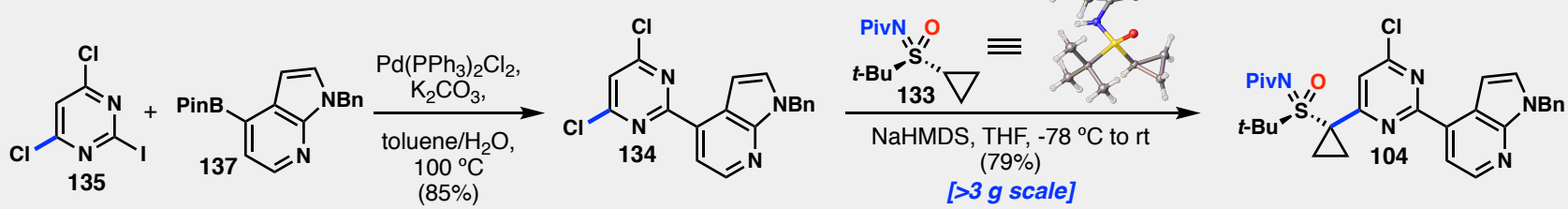

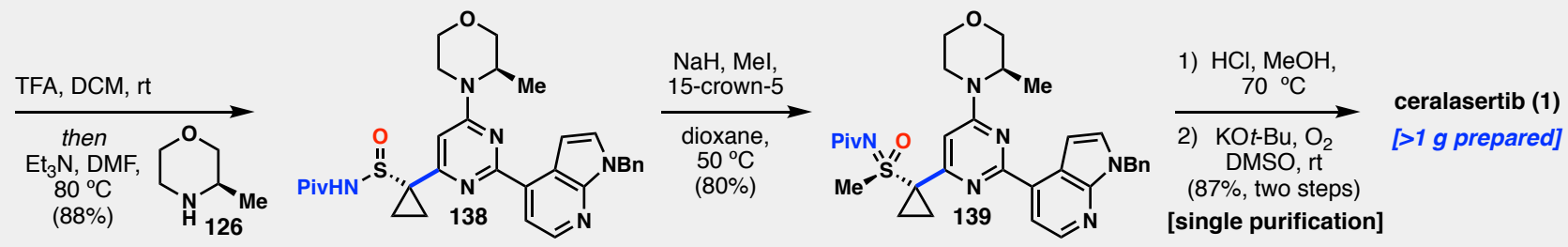

[2.8 $\mathrm{g}$ prepared in single flask]

\section{Medicinal chemistry route $\mathrm{O}=$ points of diversity}
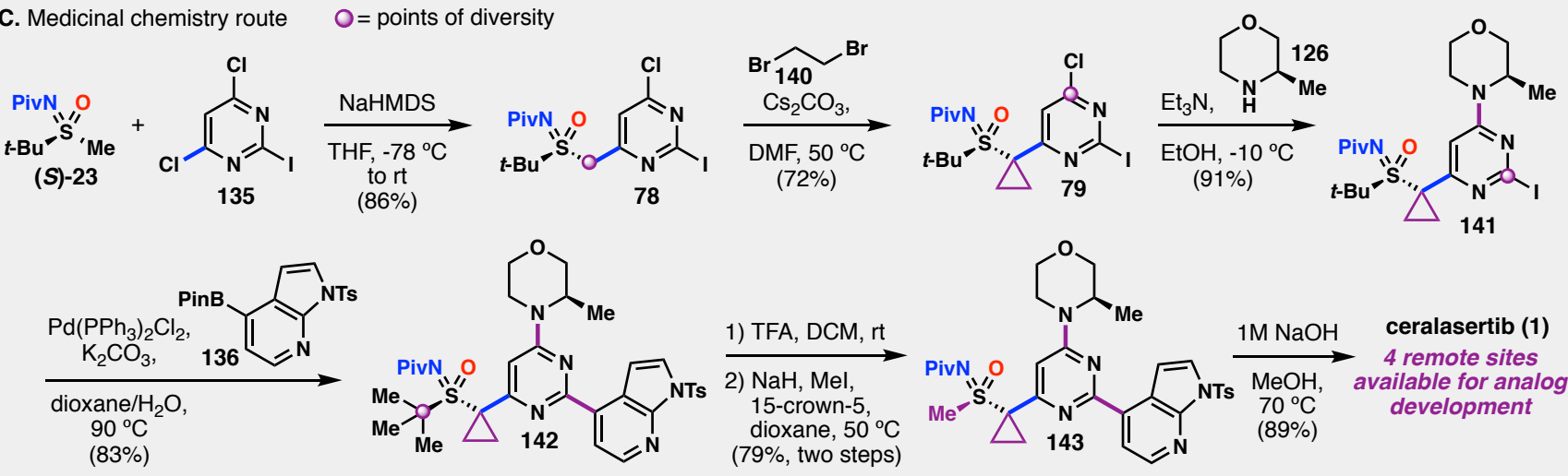

Figure 5. (A) Various routes towards ceralasertib (1) by AstraZeneca along with two sulfonimidoyl $\mathrm{S}_{N} A_{\mathrm{r}}$ routes. (B) Target-oriented gram-scale enantiospecific synthesis of $\mathbf{1}$. (C) Medicinal chemistry route to 1 via sulfonimidoyl $\mathrm{S}_{\mathrm{N}} A \mathrm{r}$ outlining points of diversity. 
A second $\mathrm{S}_{\mathrm{N}} \mathrm{Ar}$ was achieved with morpholine $\mathbf{1 2 6}$ with good regiocontrol (ca. 9:1) and high yield (91\%) at low reaction temperatures - providing advanced intermediate 141 and leaving two diversification sites remaining.

The two step $S$-alkylation sequence using 2-iodopyrimidine $\mathbf{1 4 1}$ could be employed at this point, leaving the last diversification site at the 2-position of the pyrimidine capable of eastern region analog development (see SI). However, we decided to push the boundaries of the $t$-butyl sulfoximine to determine if it were stable under typical crosscoupling conditions. To our delight, $\mathbf{1 4 1}$ underwent a Suzuki coupling with boronic ester 136 to give fully protected $t$-Bu sulfoximine $\mathbf{1 4 2}$ in $83 \%$ yield. An $S$-alkylation sequence provided methyl sulfoximine $\mathbf{1 4 3}$ that was subsequently deprotected to give ceralasertib $\mathbf{1}$, fully demonstrating the feasibility of the diversity-oriented route. The disclosed improvements made to incorporate congested sulfoximine moieties provides an alternative approach to 1 and related scaffolds. By utilizing the $\mathrm{S}_{\mathrm{N}} \mathrm{Ar}$ approach with trifunctional pyrimidine 135, the points of diversity were increased by two, the overall yield increased by $20 \%$, and the step count decreased by two.

\section{CONCLUSION}

A modular approach for the installation of sulfonimidoyl motifs via $\mathrm{S}_{\mathrm{N}} \mathrm{Ar}$ chemistry has been extensively examined and its utility demonstrated, culminating with 80 examples and 4 synthetic applications. The diversity displayed with both nucleophile and electrophile scopes exemplifies the far-reaching implications of the developed method. We fully anticipate that the method described herein will be adopted by discovery chemists interested in the unique physiochemical properties of sulfonimidoyl functional groups, with an emphasis on pharmaceutically relevant heterocycles. By removing synthetic barriers for the introduction and late-stage modifications, neglected S(VI) functionality can be incorporated into more discovery campaigns and hopefully become as commonly used as their related sulfone and sulfonamide counterparts. While developing the sulfonimidoyl $\mathrm{S}_{\mathrm{N}} \mathrm{Ar}$ method, we noted the remaining limitations in accessing enantiopure sulfoximines and sulfonimidamides. Currently, investigations into further solutions for the asymmetric introduction of sulfoximines and sulfonimidamides is ongoing in our laboratory and will be reported on in due course.

\section{ASSOCIATED CONTENT}

Supporting Information

The Supporting Information is available free of charge on the ACS Publications website.

General information, experimental details, graphical procedures, and analytical data $\left({ }^{1} \mathrm{H},{ }^{13} \mathrm{C},{ }^{19} \mathrm{~F}\right.$ NMR, MS, chiral HPLC) for all new compounds (PDF)

X-ray crystallographic data are available free of charge from the Cambridge Crystallographic Database Centre
(CCDC 2087123 (48), CCDC 2087121 (103), CCDC 2087124 (107), CCDC 2087122 (133) (CIF))

\section{AUTHOR INFORMATION}

\author{
Corresponding Author \\ * Justin M. Lopchuk \\ Email: justin.lopchuk@moffitt.org.
}

\section{Notes}

The authors declare no competing interests.

\section{ACKNOWLEDGMENT}

We thank Dr. Harshani Lawrence and Dr. Sang Yun for NMR and HRMS support; Chuan Shan and Qi Tang for assistance with X-ray crystallography. We gratefully acknowledge the Florida Department of Health (Bankhead-Coley \#9BCog) for partial support of this research. This work has also been supported in part by the Chemical Biology Core Facility at the $\mathrm{H}$. Lee Moffitt Cancer Center \& Research Institute, an NCI designated Comprehensive Cancer Center ( $\left.\mathrm{P}_{30} \mathrm{O}-\mathrm{CAo} 76292\right)$.

\section{REFERENCES}

(1) (a) Ilardi, E. A.; Vitaku, E.; Njardarson, J. T., Data-Mining for Sulfur and Fluorine: An Evaluation of Pharmaceuticals To Reveal Opportunities for Drug Design and Discovery. J. Med. Chem. 2o14, 57 (7), 2832-2842. (b) Zhao, C.; Rakesh, K. P.; Ravidar, L.; Fang, W.-Y.; Qin, H.-L., Pharmaceutical and medicinal significance of sulfur (S(VI))-Containing motifs for drug discovery: A critical review. Eur. J. Med. Chem. 2019, 162, 679-734. (c) Tang, K.-X.; Wang, C.-M.; Gao, T.-H.; Chen, L.; Fan, L.; Sun, L.-P., Transition Metal-Catalyzed C-H Bond Functionalizations by Use of SulfurContaining Directing Groups. Adv. Synth. Catal. 2019, 361 (1), 2638. (d) Wang, J.; Lakraychi, A. E.; Liu, X.; Sieuw, L.; Morari, C.; Poizot, P.; Vlad, A., Conjugated sulfonamides as a class of organic lithium-ion positive electrodes. Nat. Mater. 2o21, 20 (5), 665-673.

(2) Scott, K. A.; Njardarson, J. T., Analysis of US FDA-Approved Drugs Containing Sulfur Atoms. Top Curr Chem. 2018, 376, 5 .

(3) (a) Mäder, P.; Kattner, L., Sulfoximines as Rising Stars in Modern Drug Discovery? Current Status and Perspective on an Emerging Functional Group in Medicinal Chemistry. J. Med. Chem. 2020, 63 (23), 14243-14275. (b) Lücking, U., Sulfoximines: A Neglected Opportunity in Medicinal Chemistry. Angew. Chem. Int. Ed. 2013, 52 (36), 9399-9408. (c) Sirvent, J. A.; Lücking, U., Novel Pieces for the Emerging Picture of Sulfoximines in Drug Discovery: Synthesis and Evaluation of Sulfoximine Analogues of Marketed Drugs and Advanced Clinical Candidates. ChemMedChem 2017, 12 (7), 487-501. (d) Lücking, U., Neglected sulfur(VI) pharmacophores in drug discovery: exploration of novel chemical space by the interplay of drug design and method development. Org. Chem. Front. 2019, 6 (8), 1319-1324. (e) Devendar, P.; Yang, G. F., Sulfur-Containing Agrochemicals. Top Curr Chem. 2017, 375 (6), 82. (f) Zasukha, S. V.; Timoshenko, V. M.; Tolmachev, A. A.; Pivnytska, V. O.; Gavrylenko, O.; Zhersh, S.; Shermolovich, Y.; Grygorenko, O. O., Sulfonimidamides and Imidosulfuric Diamides: Compounds from an Underexplored Part of Biologically Relevant Chemical Space. Chem. - Eur. J. 2019, 25 (28), 6928-6940.

(4) (a) Foote, K. M.; Nissink, J. W. M.; McGuire, T.; Turner, P.; Guichard, S.; Yates, J. W. T.; Lau, A.; Blades, K.; Heathcote, D.; Odedra, R.; Wilkinson, G.; Wilson, Z.; Wood, C. M.; Jewsbury, P. J., Discovery and Characterization of AZD6738, a Potent Inhibitor of Ataxia Telangiectasia Mutated and Rad3 Related (ATR) Kinase with Application as an Anticancer Agent. J. Med. Chem. 2018, 61 (22), 9889-9907. (b) Luecking, U.; Hog, D.; Geisler, J.; Scholz, A.; Petersen, K.; Lienau, P.; Stegmann, C.; Andres, D.; Siemeister, G.; 
Werbeck, N. Preparation of modified macrocyclic compounds for the treatment of diseases. PCT Int. Patent Appl. WO 2017/060167 A1, April 13, 2017. (c) Luecking, U.; Geisler, J.; Hog, D.; Scholz, A.; Petersen, K.; Lienau, P.; Stegmann, C.; Andres, D.; Zheng, K.; Gao, P.; Chen, G.; Xi, J.; Herbert, S.; Siemeister, G.; Werbeck, N. Preparation of macrocyclic sulfondiimine compounds as $\mathrm{CDK}_{9}$ inhibitor for treatment of hyperproliferative disorder, viral infection, and cardiovascular diseases. PCT Int. Patent Appl. WO 2017/055196 A1, June 4, 2017. (d) Zhu, Y.; Loso, M. R.; Watson, G. B.; Sparks, T. C.; Rogers, R. B.; Huang, J. X.; Gerwick, B. C.; Babcock, J. M.; Kelley, D.; Hegde, V. B.; Nugent, B. M.; Renga, J. M.; Denholm, I.; Gorman, K.; DeBoer, G. J.; Hasler, J.; Meade, T.; Thomas, J. D., Discovery and Characterization of Sulfoxaflor, a Novel Insecticide Targeting Sap-Feeding Pests. J. Agric. Food Chem. 2011, 59 (7), 2950-2957. (e) Johnson, T.; Vairagoundar, R.; Ewin, R. A. Preparation of novel phenicol derivatives useful as antibacterial agents. PCT Int. Patent Appl. WO 2014/172443 Al, October 23, 2014. (f) Kosemund, D.; Luecking, U.; Scholz, A.; Siemeister, G.; Lienau, P. Preparation of sulfoximine substituted fluoro(pyridin-2-yl)pyridin-2-amine derivatives as $\mathrm{CDK}_{9}$ kinase inhibitors useful for treatment of hyperproliferative, viral, and cardiovascular diseases. PCT Int. Patent Appl. WO 2015/001021 A1, October 23, 2015.

(5) Frings, M.; Bolm, C.; Blum, A.; Gnamm, C., Sulfoximines from a Medicinal Chemist's Perspective: Physicochemical and in vitro Parameters Relevant for Drug Discovery. Eur. J. Med. Chem. 2017, 126, 225-245.

(6) Chinthakindi, P. K.; Naicker, T.; Thota, N.; Govender, T.; Kruger, H. G.; Arvidsson, P. I., Sulfonimidamides in Medicinal and Agricultural Chemistry. Angew. Chem. Int. Ed. 2017, 56 (15), 41004109.

(7) Ayaz, P.; Andres, D.; Kwiatkowski, D. A.; Kolbe, C.-C.; Lienau, P.; Siemeister, G.; Lücking, U.; Stegmann, C. M., Conformational Adaption May Explain the Slow Dissociation Kinetics of Roniciclib (BAY 1000394), a Type I CDK Inhibitor with Kinetic Selectivity for CDK2 and CDK9. ACS Chem. Bio. 2016, 11 (6), 1710-1719.

(8) Izzo, F.; Schäfer, M.; Lienau, P.; Ganzer, U.; Stockman, R.; Lücking, U., Exploration of Novel Chemical Space: Synthesis and in vitro Evaluation of N-Functionalized Tertiary Sulfonimidamides. Chem. - Eur. J. 2018, 24 (37), 9295-9304.

(9) Clinical Trials Using ATR Kinase Inhibitor AZD6738. https://www.cancer.gov/about-cancer/treatment/clinicaltrials/intervention/atr-kinase-inhibitor-azd6738 (accessed May 26, 2021).

(10) Luecking, U.; Hog, D.; Christ, C.; Sack, U.; Siegel, F.; Lienau, P.; Werbeck, N. Preparation of novel PTEFB inhibiting macrocyclic compounds. PCT Int. Patent Appl. WO 2018/177899 A1, March 22, 2018.

(11) Walker, D. P.; Zawistoski, M. P.; McGlynn, M. A.; Li, J. C.; Kung, D. W.; Bonnette, P. C.; Baumann, A.; Buckbinder, L.; Houser, J. A.; Boer, J.; Mistry, A.; Han, S.; Xing, L.; Guzman-Perez, A., Sulfoximine-substituted trifluoromethylpyrimidine analogs as inhibitors of proline-rich tyrosine kinase 2 (PYK2) show reduced hERG activity. Bioorg. Med. Chem. Lett. 2009, 19 (12), 3253-8.

(12) (a) Mc Bride, C.; Trzoss, L. L.; Boloor, A.; Sokolova, N.; Pastor, R. M.; Staben, S. T.; Stivala, C.; Volgraf, M.; Bronner, S. M. Preparation of sulfonimidamide compounds as inhibitors of interleukin-1 activity. PCT Int. Patent Appl. WO 2020/o18975 A1, January 23, 2020. (b) Chowdhury, S.; Dehnhardt, C. M.; Focken, T.; Grimwood, M. E.; Hemeon, I. W.; McKerrall, S.; Sutherlin, D. Preparation of substituted benzamides as sodium channel inhibitors and therapeutic uses thereof. PCT Int. Patent Appl. WO 2017/172802 A1, May 10, 2017.

(13) Bartels, B.; Dolente, C.; Guba, W.; Haap, W.; Kuglstatter, A.; Obst Sander, U.; Peters, J.-U.; Rogers-Evans, M.; Woltering, T.; Schnider, C.; Wermuth, R. Preparation of pyridyl-triazabicycles having BACE1 inhibitory activity. PCT Int. Patent Appl. WO 2016/012422 A1, January 28, 2016.

(14) Katz, J.; Roush, W.; Seidel, H. M.; Shen, D.-M.; Venkatraman, S. Sulfonimidamide compounds and compositions for treating conditions associated with NLRP activity. PCT Int. Patent Appl. WO 2020/154499 A1, July 30, 2020.

(15) Ouvry, G.; Bihl, F.; Bouix-Peter, C.; Christin, O.; DefoinPlatel, C.; Deret, S.; Feret, C.; Froude, D.; Hacini-Rachinel, F.; Harris, C. S.; Hervouet, C.; Lafitte, G.; Luzy, A.-P.; Musicki, B.; Orfila, D.; Parnet, V.; Pascau, C.; Pascau, J.; Pierre, R.; Raffin, C.; Rossio, P.; Spiesse, D.; Taquet, N.; Thoreau, E.; Vatinel, R.; Vial, E.; Hennequin, L. F., Sulfoximines as potent ROR $\gamma$ inverse agonists. Bioorg. Med. Chem. Lett. 2018, 28 (8), 1269-1273.

(16) Loso, M. R.; Benko, Z.; Buysse, A.; Johnson, T. C.; Nugent, B. M.; Rogers, R. B.; Sparks, T. C.; Wang, N. X.; Watson, G. B.; Zhu, Y., SAR studies directed toward the pyridine moiety of the sapfeeding insecticide sulfoxaflor (Isoclast active). Bioorg. Med. Chem. 2016, 24 (3), 378-382.

(17) SciFinder; Chemical Abstracts Service: Columbus, OH; Patent search for sulfoximine-containing compounds: structure search using general sulfoximine; https://scifindern.cas.org/search/reference/6obodgddeg1ebe7b813ae2f8/1 (accessed May 28).

(18) SciFinder; Chemical Abstracts Service: Columbus, OH; Patent search for sulfonimidamide-containing compounds: structure search using general sulfonimidamide; https://scifindern.cas.org/search/reference/6oboda8beg1ebe7b81zaezaf/1 (accessed May 28).

(19) SciFinder; Chemical Abstracts Service: Columbus, OH; Patent search for sulfondiimine-containing compounds: structure search using general sulfondiimine; https://scifindern.cas.org/search/reference/6obodaegeg1ebe7b813ae41a/1 (accessed May 28).

(20) (a) Okamura, H.; Bolm, C., Rhodium-Catalyzed Imination of Sulfoxides and Sulfides: Efficient Preparation of $\mathrm{N}$ Unsubstituted Sulfoximines and Sulfilimines. Org. Lett. 2004, 6 (8), 1305-1307. (b) Correa, A.; Bolm, C., Ligand-free coppercatalyzed N-arylation of nitrogen nucleophiles. Adv. Synth. Catal. 2007, 349 (17+18), 2673-2676. (c) Cheng, Y.; Bolm, C., Regioselective Syntheses of 1,2-Benzothiazines by RhodiumCatalyzed Annulation Reactions. Angew. Chem. Int. Ed. 2015, 54 (42), 12349-12352.

(21) (a) Zenzola, M.; Doran, R.; Luisi, R.; Bull, J. A., Synthesis of Sulfoximine Carbamates by Rhodium-Catalyzed Nitrene Transfer of Carbamates to Sulfoxides. J. Org. Chem. 2015, 80 (12), 63916399. (b) Zenzola, M.; Doran, R.; Degennaro, L.; Luisi, R.; Bull, J. A., Transfer of Electrophilic NH Using Convenient Sources of Ammonia: Direct Synthesis of NH Sulfoximines from Sulfoxides. Angew. Chem., Int. Ed. 2016, 55 (25), 7203-7207. (c) Tota, A.; Zenzola, M.; Chawner, S. J.; John-Campbell, S. S.; Carlucci, C.; Romanazzi, G.; Degennaro, L.; Bull, J. A.; Luisi, R., Synthesis of $\mathrm{NH}$-sulfoximines from sulfides by chemoselective one-pot $\mathrm{N}$ - and O-transfers. Chem. Commun. 2017, 53 (2), 348-351.

(22) Johnson, C. R., Utilization of sulfoximines and derivatives as reagents for organic synthesis. Acc. Chem. Res. 1973, 6 (10), 341347

(23) (a) Sirvent, J. A.; Bierer, D.; Webster, R.; Lücking, U., Palladium-Catalyzed Direct $\alpha$-Arylation of p-MethoxybenzylProtected S,S-Dimethylsulfoximine. Synthesis 2017, 49 (05), 10241036. (b) Greed, S.; Briggs, E. L.; Idiris, F. I. M.; White, A. J. P.; Luecking, U.; Bull, J. A., Synthesis of Highly Enantioenriched Sulfonimidoyl Fluorides and Sulfonimidamides by Stereospecific Sulfur-Fluorine Exchange (SuFEx) Reaction. Chem. - Eur. J. 2020, 26 (55), 12533-12538. (c) Izzo, F.; Schaefer, M.; Stockman, R.; Luecking, U., A New, Practical One-Pot Synthesis of Unprotected Sulfonimidamides by Transfer of Electrophilic $\mathrm{NH}$ to Sulfinamides. Chem. - Eur. J. 2017, 23 (60), 15189-15193. 
(24) (a) Aota, Y.; Kano, T.; Maruoka, K., Asymmetric Synthesis of Chiral Sulfoximines through the S-Alkylation of Sulfinamides. Angew. Chem. Int. Ed. 2019, 58 (49), 17661-17665. (b) Aota, Y.; Kano, T.; Maruoka, K., Asymmetric Synthesis of Chiral Sulfoximines via the S-Arylation of Sulfinamides. J. Am. Chem. Soc. 2019, 141 (49), 19263-19268.

(25) (a) Gao, B.; Li, S.; Wu, P.; Moses, J. E.; Sharpless, K. B., SuFEx Chemistry of Thionyl Tetrafluoride (SOF4) with Organolithium Nucleophiles: Synthesis of Sulfonimidoyl Fluorides, Sulfoximines, Sulfonimidamides, and Sulfonimidates. Angew. Chem., Int. Ed. 2018, 57 (7), 1939-1943. (b) Zheng, Q.; Woehl, J. L.; Kitamura, S.; Santos-Martins, D.; Smedley, C. J.; Li, G.; Forli, S.; Moses, J. E.; Wolan, D. W.; Sharpless, K. B., SuFExenabled, agnostic discovery of covalent inhibitors of human neutrophil elastase. Proc. Natl. Acad. Sci. U.S.A. 2019, 116 (38), 188o8. (c) Kitamura, S.; Zheng, Q.; Woehl, J. L.; Solania, A.; Chen, E.; Dillon, N.; Hull, M. V.; Kotaniguchi, M.; Cappiello, J. R.; Kitamura, S.; Nizet, V.; Sharpless, K. B.; Wolan, D. W., Sulfur(VI) Fluoride Exchange (SuFEx)-Enabled High-Throughput Medicinal Chemistry. J. Am. Chem. Soc. 2020, 142 (25), 10899-10904.

(26) (a) Davies, T. Q.; Hall, A.; Willis, M. C., One-Pot, ThreeComponent Sulfonimidamide Synthesis Exploiting the Sulfinylamine Reagent N-Sulfinyltritylamine, TrNSO. Angew. Chem. Int. Ed. 2017, 56 (47), 14937-14941. (b) Zhang, Z.-X.; Davies, T. Q.; Willis, M. C., Modular Sulfondiimine Synthesis Using a Stable Sulfinylamine Reagent. J. Am. Chem. Soc. 2019, 141 (33), 13022-13027. (c) Davies, T. Q.; Tilby, M. J.; Ren, J.; Parker, N. A.; Skolc, D.; Hall, A.; Duarte, F.; Willis, M. C., Harnessing Sulfinyl Nitrenes: A Unified One-Pot Synthesis of Sulfoximines and Sulfonimidamides. J. Am. Chem. Soc. 2020, 142 (36), 15445-15453.

(27) (a) Pyne, S. G.; Dong, Z.; Skelton, B. W.; White, A. H., Cyclopropanation reactions of enones with lithiated sulfoximines: application to the asymmetric synthesis of chiral cyclopropanes. J. Org. Chem. 1997, 62 (8), 2337-2343. (b) Zhang, W.; Wang, F.; Hu, J., N-Tosyl-S-difluoromethyl-S-phenylsulfoximine: A New Difluoromethylation Reagent for S-, N-, and C-Nucleophiles. Org. Lett. 2009, 11 (10), 2109-2112. (c) Shen, X.; Liu, Q.; Zhang, W.; Hu, J., Stereoselective Synthesis of (Sulfonimidoyl)cyclopropanes with (R)-PhSO(NTs) $\mathrm{CH}_{2} \mathrm{Cl}$ and $\alpha, \beta$-Unsaturated Weinreb Amides: Tuning the of Selectivity between $\mathrm{C}-\mathrm{Cl}$ and $\mathrm{C}-\mathrm{S}$ Bond Cleavage. Eur. J. Org. Chem. 2016, 2016 (5), 906-909.
(28) Cho, G. Y.; Bolm, C., Palladium-catalyzed $\alpha$-arylation of sulfoximines. Org. Lett. 2005, 7 (7), 1351-1354.

(29) Haake, M., Ein neues verfahren zur darstellung von S,Sdialkylschwefeldiimiden. Tetrahedron Lett. 1970, 11 (51), 44494450.

(30) Park, S. J.; Baars, H.; Mersmann, S.; Buschmann, H.; Baron, J. M.; Amann, P. M.; Czaja, K.; Hollert, H.; Bluhm, K.; Redelstein, R.; Bolm, C., N-cyano sulfoximines: COX inhibition, anticancer activity, cellular toxicity, and mutagenicity. ChemMedChem 2013, 8 (2), 217-20.

(31) (a) Murray, J. M.; Sweeney, Z. K.; Chan, B. K.; Balazs, M.; Bradley, E.; Castanedo, G.; Chabot, C.; Chantry, D.; Flagella, M.; Goldstein, D. M.; Kondru, R.; Lesnick, J.; Li, J.; Lucas, M. C.; Nonomiya, J.; Pang, J.; Price, S.; Salphati, L.; Safina, B.; Savy, P. P. A.; Seward, E. M.; Ultsch, M.; Sutherlin, D. P., Potent and Highly Selective Benzimidazole Inhibitors of PI3-Kinase Delta. J. Med. Chem. 2012, 55 (17), 7686-7695. (b) Kang, D.; Fang, Z.; Huang, B.; Lu, X.; Zhang, H.; Xu, H.; Huo, Z.; Zhou, Z.; Yu, Z.; Meng, Q.; Wu, G.; Ding, X.; Tian, Y.; Daelemans, D.; De Clercq, E.; Pannecouque, C.; Zhan, P.; Liu, X., Structure-Based Optimization of Thiophene[3,2-d]pyrimidine Derivatives as Potent HIV-1 Nonnucleoside Reverse Transcriptase Inhibitors with Improved Potency against Resistance-Associated Variants. J. Med. Chem. 2017, 60 (10), 4424-4443.

(32) Goundry, W. R. F.; Dai, K.; Gonzalez, M.; Legg, D.; O'Kearney-McMullan, A.; Morrison, J.; Stark, A.; Siedlecki, P.; Tomlin, P.; Yang, J., Development and Scale-up of a Route to ATR Inhibitor AZD6738. Org. Process Res. Dev. 2019, 23 (7), 1333-1342.

(33) Graham, M. A.; Askey, H.; Campbell, A. D.; Chan, L.; Cooper, K. G.; Cui, Z.; Dalgleish, A.; Dave, D.; Ensor, G.; Galan Espinosa, M. R.; Hamilton, P.; Heffernan, C.; Jackson, L. V.; Jing, D.; Jones, M. F.; Liu, P.; Mulholland, K. R.; Pervez, M.; Popadynec, M.; Randles, E.; Tomasi, S.; Wang, S., Development and Scale-Up of an Improved Manufacturing Route to the ATR Inhibitor Ceralasertib. Org. Process Res. Dev. 2021, 25 (1), 43-56.

(34) Graham, M. A.; Noonan, G.; Cherryman, J. H.; Douglas, J. J.; Gonzalez, M.; Jackson, L. V.; Leslie, K.; Liu, Z.-q.; McKinney, D.; Munday, R. H.; Parsons, C. D.; Whittaker, D. T. E.; Zhang, E.-X.; Zhang, J.-w., Development and Proof of Concept for a Large-Scale Photoredox Additive-Free Minisci Reaction. Org. Process Res. Dev. 2021, 25 (1), 57-67. 